\title{
CORN AND SOYBEAN YIELD INDICATORS USING REMOTELY SENSED VEGETATION INDEX
}

\author{
Minghua Zhang ${ }^{1}$, Michael O’Neill ${ }^{2}$, Paul Hendley ${ }^{1}$, Dirk Drost ${ }^{1}$ and Susan \\ Ustin $^{2}$ \\ ${ }^{\text {I} Z}$ Zeneca Ag Products, 1200 S 47 $7^{\text {th }}$. Street, Richmond, CA 94804-0023 \\ ${ }^{2}$ Department of Land, Air and Water Resources, University of California, Davis \\ 95616
}

\begin{abstract}
Precision farming involves crop management in parcels smaller than field size. Yield prediction models based on early growth stage parameters are one desired goal to enable precision farming approaches to improve production. To accomplish this goal, spatial data at a suitable scale describing the variability of yield, crop condition at certain growth stages, soil nutrient status, agronomic factors, moisture status, and weed/pest pressures are required.

This paper discusses the potential application of aerial imaging to monitor and predict the potential yield for corn and soybean at various growth stages in the season. Included in the analyses were aerial images, yield monitor data and soil grid sampling. The relationship between remotely sensed Normalized Difference Vegetation Index (NDVI) and yield was best at $9 \mathrm{~m}$ spatial resolution. Preliminary results indicate that it is possible to use NDVI to estimate the potential yield for soybean and corn when canopy reaches full cover.
\end{abstract}

\section{INTRODUCTION}

Precision farming is a new agricultural system concept with the goals of optimizing returns in agricultural production and environment. This concept involves the development and adoption of remote sensing (Barnes et al., 1996), and Geographic Information System (GIS) technology applications, and knowledge-based technical management systems (NRC, 1997). With a refined GIS and spatial knowledge-based management system, farmers should have the ability to appropriately manage field operations at each location in the field, as well as the ability to predict likely yield from early season indicators.

Many studies have focused on variable rate applications (Gotway et al, 1996; Stafford and Miller, 1996) while some are focused on yield mapping (Sudduth and Drummond, 1996). Yield mapping provides not only information about the yield itself, but it allows comparison to field conditions that may explain spatial yield variation. However, yield mapping is normally accomplished only once, at the end of a season. It is difficult to quantitatively evaluate efficacy of management because many factors that 
comprise the measured value change over successive seasons (Blackmore and Marshall, 1996; Davis, 1998). Over the longer term, the combined technologies of variable rate applications and yield mapping allows analyses of individual variables and their correlation to crop production between seasons. Remote sensing from airborne or spaceborne sensors can provide spatially distributed synoptic data acquired multiple times during the growing season. The normalized ratio of near-infrared reflectance to red reflectance, called the normalized difference vegetation index (NDVI) has been shown to be a sensitive indicator of biomass and leaf area in several crops, which can be used to track crop development over the season. Because crop yield is generally correlated with canopy development, this index can be used to develop a relationship to yield. Once a relationship between yield and NDVI is developed, then farmers can predict their yield earlier in the growing season and therefore, better harvest management, planing the following season's inputs, and other more effective management can be achieved.

To explore the potential for corn and soybean yield prediction, the study objectives were: (1) to monitor Midwest row crop growth during the growing season through aerial images, (2) to understand the relationship between crop yield and NDVI, (3) to investigate the optimum image spatial scale for the best performance in yield prediction, and (4) to examine the relationships between NDVI and soil nutrients.

\section{MATERIALS AND METHODS}

Corn and soybean fields near Hills, Iowa (Figure 1) were selected for study. Hills is situated in a small valley located south of Iowa City. Most agriculture in the region is rainfed and the growing season normally starts early in May with harvesting in late September or October. Soils are generally rich in organic matter. The selected corn field, planted April 24, 1997, was approximately 46 acres in size. The selected soybean field, planted May 10 1997, was approximately 110 acres in size. There were no specific pest pressures influencing crop growth in either field.

Aerial images of both fields were obtained three times $(6 / 17,7 / 16,9 / 18$ in 1997) during the growing season using the ADAR 5500 4-band digital camera. The 4-spectral band intervals were filtered to match Landsat Thematic Mapper blue, green, red, and nearinfrared bands. The airplane was flown at an altitude of approximately 7300 feet to provide ground spatial resolution of $1 \mathrm{~m}$. Yield monitor data, recorded as a flow rate, and harvest speed were measured at two second intervals. Soil was sampled at $100 \mathrm{~m}$ by $100 \mathrm{~m}$ grid, and the major nutrients of N,P,K and minor nutrients of $\mathrm{Ca}^{++}, \mathrm{Mg}^{++}$were analyzed.

The images, yield and soil data were georeferenced into a common coordinate, UTM zone 15 with no shift parameters. The NDVI was derived by ratio (NIR-R/NIR+R) from the aerial images for the selected fields. Various scales were resampled from the original $1 \mathrm{~m}$ resolution image and two second flow yield monitor point data in a raster environment. These scales included $1 \mathrm{~m}, 3 \mathrm{~m}, 6 \mathrm{~m}, 9 \mathrm{~m}$, and $12 \mathrm{~m}$.

ENVI image processing software (RSI Inc.), Arc/Info GRID and ArcView GIS software (ESRI, 1997) and SAS statistical software (SAS, 1996) were used for the data analysis. MS Excel was used for the graphs. 


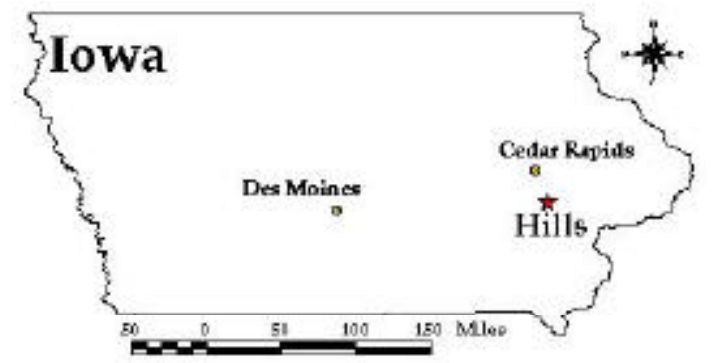

Figure 1. Study location in Hills, Iowa.

\section{RESULTS AND DISCUSSION}

The NDVI maps and the false color composite images, which are comprised of green, red and near-infrared bands, clearly displayed anomalies in the corn and soybean fields at the 1 meter spatial resolution. From the cropping history, these field patterns are associated with the agronomic variables which are used to assist farmers in field scouting and farm management decisions. The analysis results indicated a strong correlation between corn and soybean yields and NDVI in both June and July images. Figure 2 displayed the similar spatial patterns in yield and NDVI for both corn and soybean crops.

a.

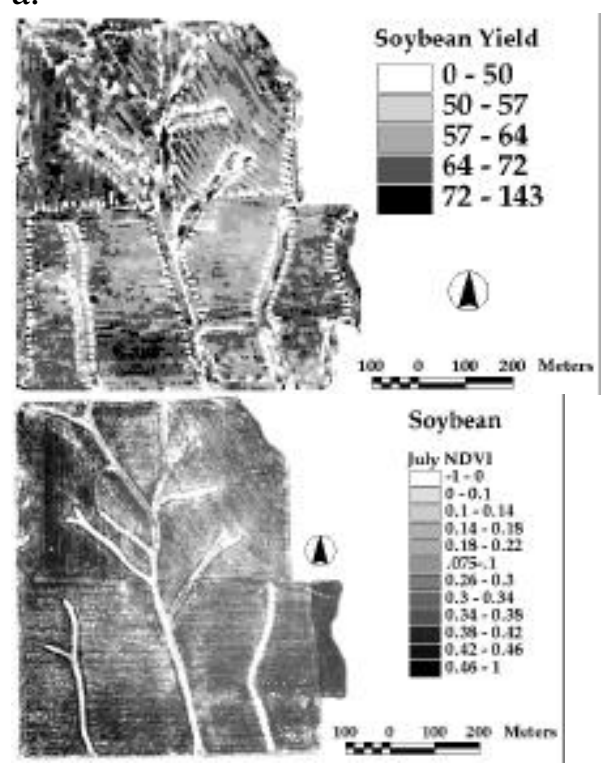

Figure 2. a. Soybean yield map and July NDVI map for the field. b.
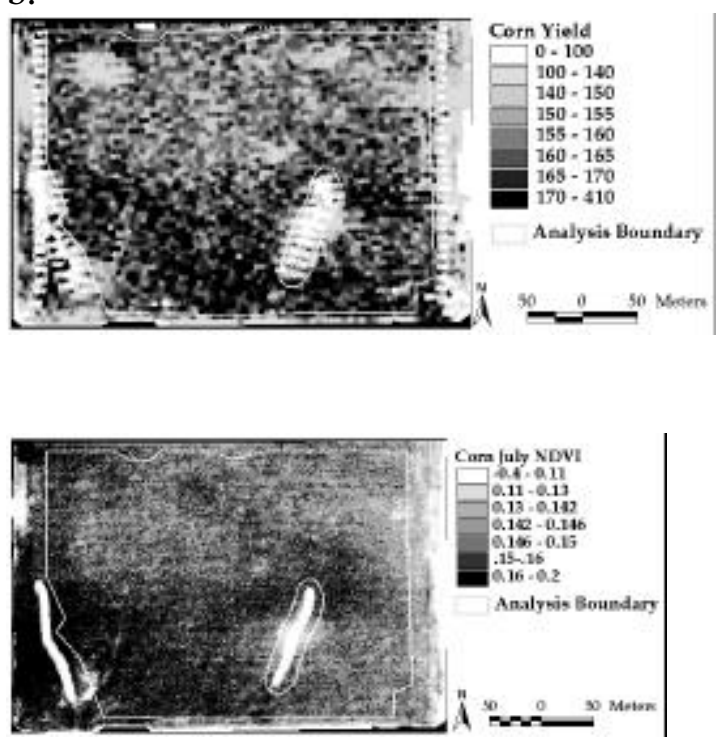

Figure 2. b. Corn yield map and July NVDI map for the field.

Our analysis showed that more than $70 \%$ of yield variation can be explained by aerial imaged NDVI for both corn and soybean crops when the NDVI values were grouped into fine intervals. The relationships for NDVI yield estimates from both June and July images 
were significant; however, the estimates from the July images were better yield predictors. These results may be attributed to the facts that the crops had reached full cover in July, the vegetation spectral signals were maximized, and the soil exposures were minimized in the images.

Comparisons of NDVI yield estimates from various spatial scales indicated that 9 to $12 \mathrm{~m}$ spatial resolution produced the highest $\mathrm{R}^{2}$, which provided the best fit in both corn and soybean (Figure 3 ). The optimum scale may be associated with the planting variables and the machinery used in the field yield mapping as well as the quality of data collection. This scale also allows capturing the soil anomaly variation present in these fields. Corn and soybean were planted in approximately 30-inch row spaces. Most corn and soybean machinery cover more than 1 meter in width, therefore it is difficult to precisely match field measurements to $1 \mathrm{~m}$ resolution imagery. In fact, the yield harvester was at least 6 meters in width.

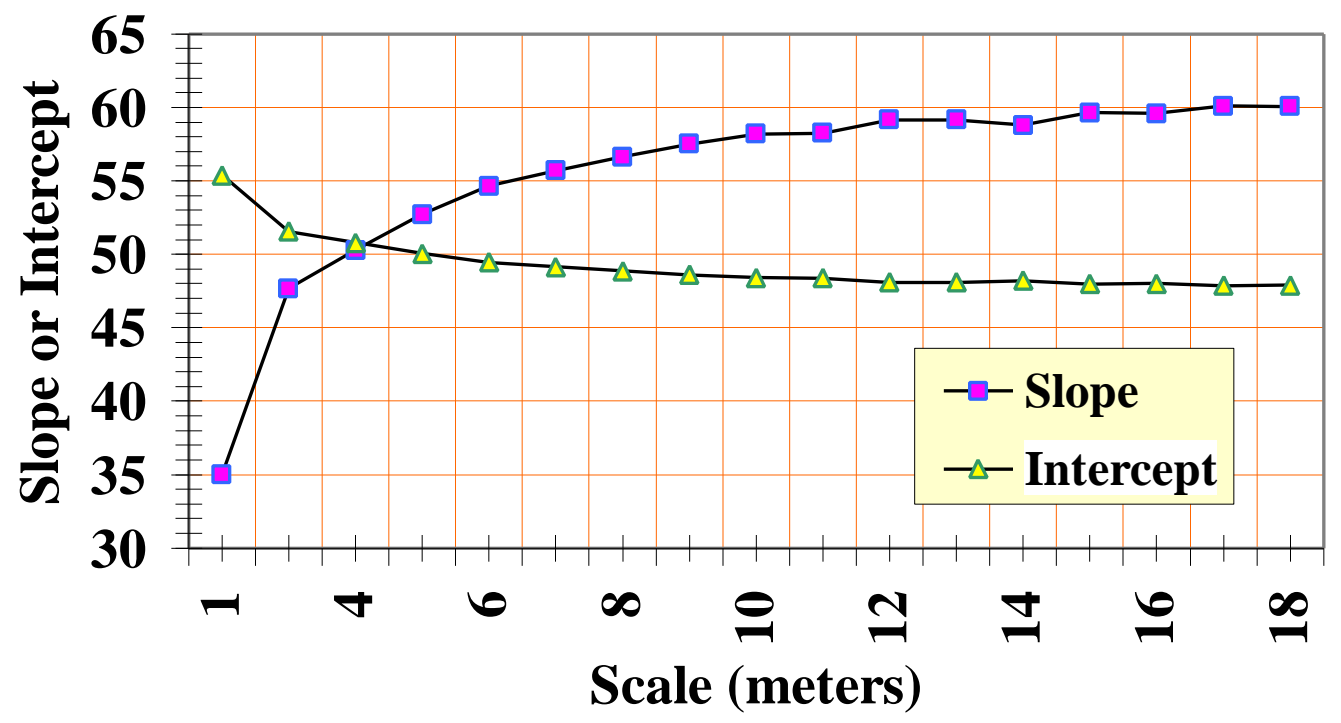

Figure 3. Slope and interception versus the scale changes in input data.

The quality of the yield monitor data depends on the variation of the topography and how uniformly the harvester is driven since the yield data were recorded every two seconds as a flow rate. As Blackmore and Marshall (1996) pointed out, there were seven potential error sources associated with yield data collection. These sources included unknown crop width in the header during the harvest, time lag of grain through the threshold machine, wandering error from GPS readings, surging grain through the combine transport system, grain loss from the combine, sensor accuracy, and calibrations. Therefore, it makes sense that data around 9 to $12 \mathrm{~m}$ spatial resolution would reveal the more robust results since the variations of yield recording can be averaged, and the random and systematic variations of both NDVI and yield can be reduced.

The results also showed that there was an increase in $\mathrm{R}^{2}$ for yield estimates with the increased resampling from $1 \mathrm{~m}$ up to $9 \mathrm{~m}$ on NDVI while yield data stayed at $1 \mathrm{~m}$. The magnitude of increased $\mathrm{R}^{2}$ was larger for yield estimates when the yield data were resampled from $1 \mathrm{~m}$ up to $9 \mathrm{~m}$ while NDVI stayed at $1 \mathrm{~m}$. The results indicated the 
sensitivity of scaling yield data to a proper scale in order to find the meaningful yield estimates using NDVI.

The residue map of the corn field using $9 \mathrm{~m}$ data inputs (Figure 4) was based on the differences between the predicted yield map and actual yield map. The various ranges identified in the residue map show the spatial locations of the unmatched predictions. The histogram (Figure 5) indicated that $70 \%$ of correct yield estimates were within $+/-5 \mathrm{bu} / \mathrm{ac}$; $90 \%$ of correct yield estimates were within $+/-9$ bu/ac.

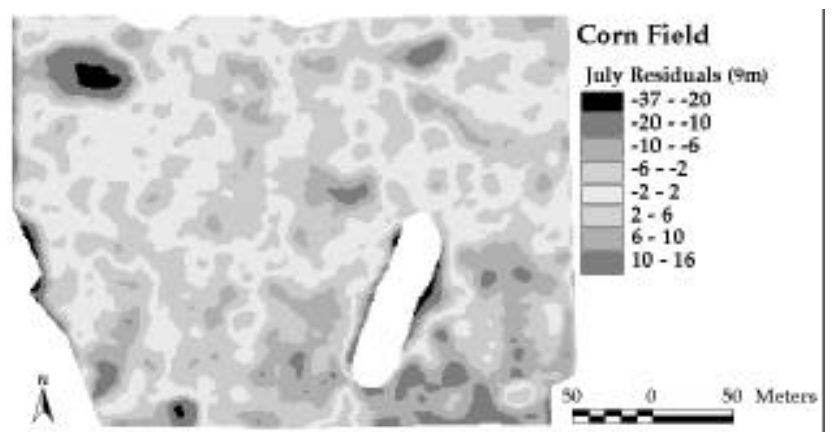

Figure 4. Spatial distribution of the residue map for the corn field. The lighter colors represent well-matched yield predictions and the darker colors are the unmatched yield predictions.

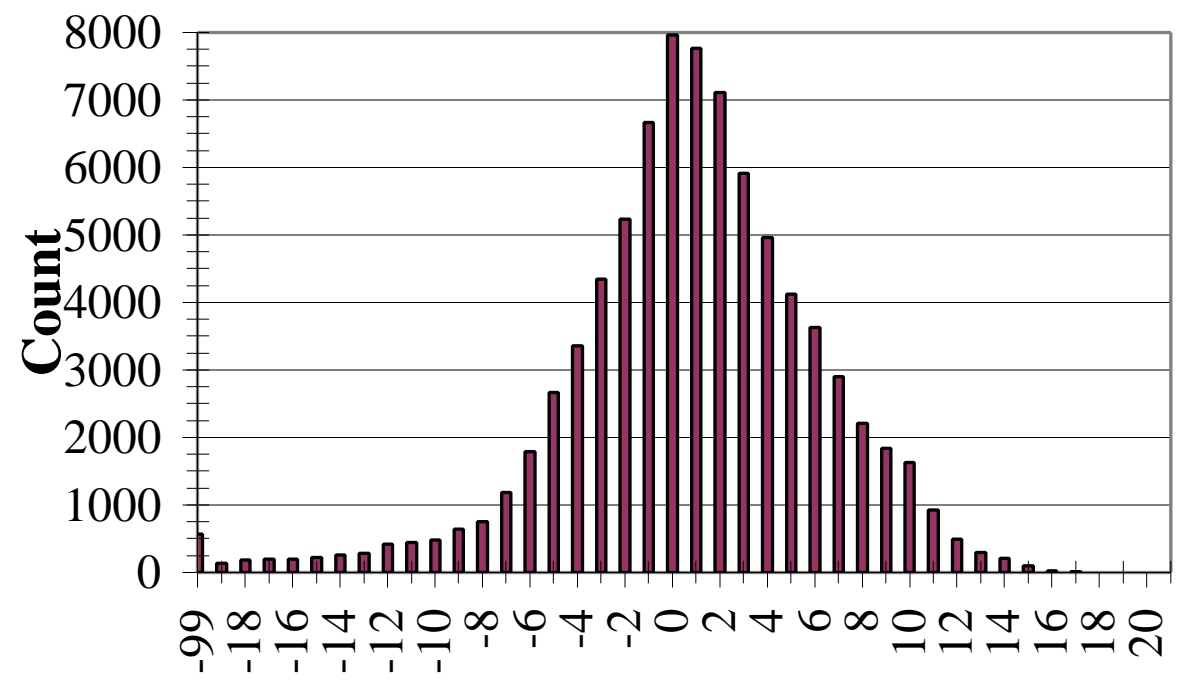

Residual

Figure 5. Residue histogram. For most pixels, the difference between the predicted yield and the actual recorded yield was within $5 \mathrm{bu} / \mathrm{ac}$.

There is a general hypothesis that yield is a function of soil nutrient variables in addition to environmental factors. Therefore, a relationship between yield and soil nutrients was expected. However, with the given data, we found no direct spatial relationship between yield and soil nutrients, and no direct relationship between NDVI and soil nutrients. This result may be due to the soil data quality and the inconsistent spatial 
scales of the yield, aerial images and soil nutrients. Hence, future analysis should include higher resolution of soil data, better accounting for the environmental factors, and middle season pest pressures.

Since field conditions and nutrients vary from field to field, one linear regression developed from one condition is not adequate to predict the yield for other fields.

However, developing this type of relationship in multiple fields could provide farmers with information for site-specific management.

Understanding the field agronomic features is important in performing precision farming, and data quality is often another key to help us correctly understand spatial variation in agricultural landscape structures and temporal variations at a given field (Franzen et al, 1996). It is common knowledge that spatial data for precision farming is collected from various sources and in different formats. Yield data are often downloaded from yield monitors, soils from grid sampling, images from various aerial vendors and/or satellites, and agronomic features from farmer's growing history. To continue to improve our understanding of these relationships, it is critical to develop more precise location information for samples and to consider new strategies to optimize soil sampling procedures. For future work, multiple fields should be studied and better image calibration using a common base should be developed to achieve the yield predictability.

\section{CONCLUSIONS}

From the analyses, we found that aerial images provide farmers with the knowledge needed to monitor crop growth, identify some of field anomalies, and efficiently direct the field scouting person to the anomalies. This knowledge is very important for short growing season crops such as vegetables and other high value cash crops in order to perform on time field management for the crops. However, it may not be as important for corn and soybean row crops. We also concluded that the better image yield prediction was found when crop reached full cover for corn and soybean crops, and the best yield estimates were obtained with $9 \mathrm{~m}$ resampled yield monitor data and NDVI data. The scaling effects of yield monitor data was more sensitive than the scaling effects of resampled NDVI images. Our preliminary results showed that NDVI can serve as an early indicator for corn and soybean yield estimates in Iowa.

In order to best use the data and the results, we need to have a better understanding of the impact of combining multiple errors into assessments. Though the data quality and potential error sources for each of the variables may potentially impede understanding of agricultural process and limit the rate at which technology applications are adopted in precision agriculture, the results from this study demonstrated yield prediction up to three months before harvest, and addressed the choice of sampling scales for data collection. Nonetheless, more work is needed to determine the optimum strategy for correlating yield maps with NVDI to determine and verify apparent relationships. The image calibration and analysis methods need further research to improve the reliability of interpretations for technology applications in precision farming. 


\section{ACKNOWLEDGEMENT}

We would like to acknowledge Zeneca Ag products for providing the funding for the project and would like to thank useful comments from the colleagues in Zeneca and the University of California Davis.

\section{REFERENCES}

Barnes, E.M., M.S. Moran, P.J. Pinter, Jr., and T.R. Clarke. Multispectral remote sensing and site-specific agriculture: examples of current technology and future possibilities. Proceedings of the $3^{\text {rd }}$ International Conference. June 23-26, 845-854.

Blackmore, B.S. and C.J. Marshall. 1996. Yield mapping: errors and algorithms. Proceedings of the $3^{\text {rd }}$ International Conference. June 23-26, 403-415.

Davis, G. 1998. Space age farming - aerial sensor applications for precision farming and management. Modern Agriculture. 1(5): 18-20.

ESRI. 1996. ARC/INFO GIS 7.04 software manuals.

Franzen, D.W., L.J. Cihacek and V.L. Hofman. 1996. Variability of soil nitrate and phosphate under different landscapes. Proceedings of the $3^{\text {rd }}$ International Conference. June 23-26, 521-529.

Gotway, CA, R.B. Ferguson and G.W. Hergert. 1996. The effects of mapping and scale on variable rate fertilizer recommendations for corn. Proceedings of the $3^{\text {rd }}$ International Conference. June 23-26, 321-330.

NRC. 1997. Committee on Assessing Crop Yield: Site-specific farming, information systems, and research opportunities, National Academy Press, 118 pp.

SAS Institute, Inc. 1996. SAS/STAT user's guide. Statistics. Release 6.08 edition, Cary, NC.

Sudduth, K.A., S.T. Drummond, S.J. Birrell and N.R. Kitchen. 1996. Analysis of spatial factors influencing crop yield. Proceedings of the $3^{\text {rd }}$ International Conference. June 23-26, 129-149.

Stafford, JV and P.C.H. Miller. 1996. Spatially variable treatment of weed patches. Proceedings of the $3^{\text {rd }}$ International Conference. June 23-26, 465-474. 